\title{
An Applied Experimental Research of the New Type LNG Rapidly Gasification Device
}

\author{
Xin-Yue Zhang ${ }^{1}$, Ping Yan ${ }^{2}$, Wei-Wu Cao ${ }^{3}$ \\ Shanghai University of Engineering Science, Shanghai, China ${ }^{1,2,3}$
}

\begin{abstract}
The liquefied natural gas (LNG) must be gasified before it is used, so the LNG heated and gasified device is very important for LNG used effectively. This paper studied and developed a new type LNG rapidly gasified device. The device adopts several creative techniques, such as the umbrella rotor, the flue gas recirculation system and the water injection system, which are authorized national invention patents. By using these techniques, the device can be operated safely and effectively. Based on the experimental research, the industrial applied device was made up, and the industrial test research has been carried on in a LNG supplied station for reasonability of the device. The results show that: the efficiency of device, the heat loss of exhausting flue gas, the heat loss of surface diffused and the fuel gas consumption rate of device have all reached the design requirements. When the load of device is in the region of 1800$2200 \mathrm{Nm} 3 / \mathrm{h}$, the efficiency of the device is all above $95 \%$; when the load is $1976.0 \mathrm{Nm} 3 / \mathrm{h}$ which is near the design value $2000 \mathrm{Nm} 3 / \mathrm{h}$, the efficiency arrives to high value $96.34 \%$. The largest load can arrive to $2800 \mathrm{Nm} 3 / \mathrm{h}$, so the device has good load adaptability which can adapt to the rapid increase of external load. The fuel gas consumption rate of device is only $1.46 \%$, which can meet the requirement of energy conservation. The new type LNG rapidly gasified device has many merits such as high efficiency, quickly starting up, fast gasified speed, compact structure, without being limited by any environmental conditions and so on. The new device may be used in middle or small independent region which cannot be joined into natural gas supplied lines system due to various reasons.
\end{abstract}

Keywords: LNG gasified device; quick start; high gasification reaction rate; umbrella rotor; flue gas recirculation; water injection system; application experiment

LNG is a kind of clean energy, which is widespread use because of its efficient use, cleaning and its convenient storage and transportation. In the area of town or some place that not suitable for large-scale networking; LNG is often used as the source gas. In the areas of load of network or emergency stockpile, LNG is selected as the first choice of reserve source.

In order to ensure the LNG gasification quickly put into use, this system must deploy LNG heating gasification unit. Therefore, it's necessary to develop a type of quick start LNG gasification device with high gasification rate, we expect this device won't be affected by environmental constraints, and will do some experimental study on this device [1-5].

\section{THE WORKING PRINCIPLE OF THE NEW LNG QUICKLY GASIFICATION DEVICE}

As shown in Figure 1, the fuel burn in the combustion chamber and produce high temperature flue gas. The highspeed gas spurt from the jet, hit the umbrella rotor which is set under the jet and half bottom in the water.

With the guidance of circular arc surface of rotor, the flue gas hit the water and splash out the water mist; evaporate the water vapor at the same time.

Under the guidance of induced draft fan, the wet smoke flow upward to the circular passage between the shell and the combustor. The smoke exchange heat with the flowing LNG When they flow through the upper coiler in the passage. Some smoke injection into the atmosphere, others flow into the loop jacket and reflow to the cone nozzle, then spurt from the nozzle with the burned smoke, which can strengthen the effect of the hitting water.

In this way, we can control the temperature of the smoke in the upper coil, to ensure the gas temperature is lower than the safe temperature.

At the same time, this control can make the steam in the smoke change phase and strengthened heat transfer. The design of the heat transfer surface is the spiral coil form up and down, the upper coil encompass the outside cylinder from bottom to top, which is used for heating gasification LNG.

The downward coils are submerged in the water to heat the gasification LNG to achieve the process parameters and apply to engineering practice [6-9].

1.burner interface 2.combustion chamber shell 3.circular flue gas imports 4.burning cylinder outside 5.circular flue gas jacket 6.smoke outlet 7.upper coil 8.flue gas nozzle 9.imports of the upper coil 10.airflow rotating 11.water gauge interface 12.export of the lower coil 13.pipe weep 14.import of the bottom wall tube 15.bottom coil 16.pool 17.water inlet 18.peep door 19.outlet of the upper coil 20.circular filling water pipe 
20

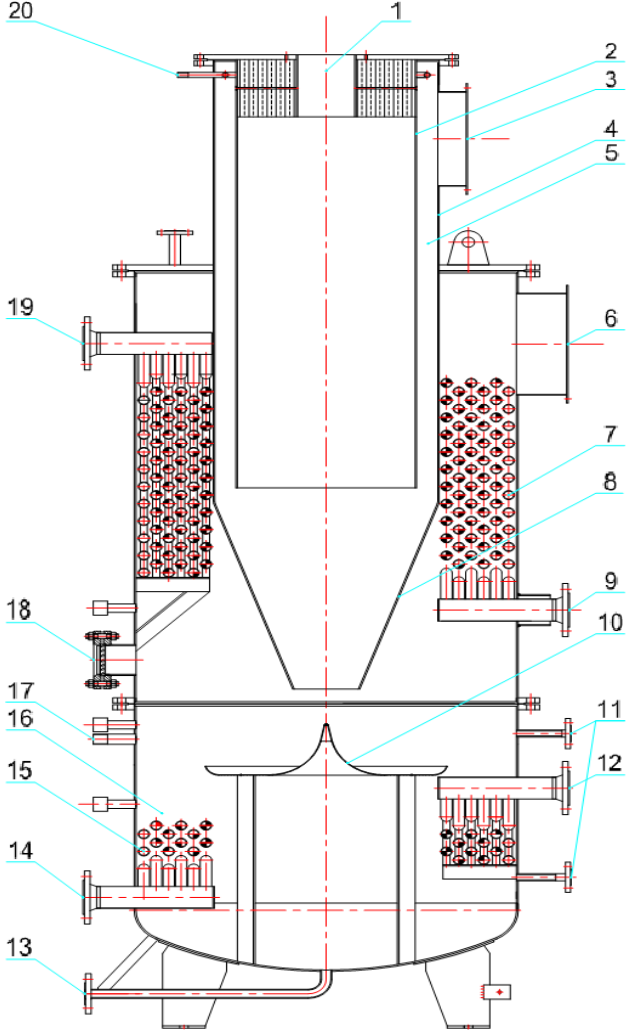

Fig. 1 the structure diagram of the new LNG rapidly gasification industrial application device

\section{THE STRUCTURE DESIGN CHARACTERISTICS AND INNOVATION OF THE NEW LNG}

\section{GASIFICATION DEVICE}

The new LNG gasification device has set the unique combustion heated and flue gas recycling system, heat transfer surface arrangement, working medium flow and water system. The umbrella airflow rotating device, the inside and outside cylinder of the combustion chamber, the tapered gas nozzle, the flue gas recirculation system and the automatic filling system are all innovative design[1012].

2.1 the innovative design of the airflow rotating device

The airflow rotating device is an original technological innovation, which is a key position of the LNG gasification equipment. The configuration is a circular curve to ensure the vertical downward smoke change into the tangential direction; this can lower the temperature of the smoke and increase its humidity. When the hypothermal smoke from the conical nozzle hit the rotating device, the smoke flow along the circular arc surface change into the tangential gas and suck the water drop to be water flue gas, then flow upward. in this process, the water take heat and evaporate, while the exhaust gas heat the water and lower its temperature, and take the heat transfer with the LNG in the coil. The advantage of the technology project: First, the high temperature flue gas exchange heat with a lot of water to reduce the temperature, which can ensure the temperature of flue gas is lower than the ignition point of LNG[13] and make the gasification equipment operate safety. Second, this device narrow the gap of the temperature difference between inside and outside of the heating surface, to avoid the damage from thermal stress. Thirdly, the steam in the exhaust gas congeal and give out heat to improve the effect of heat transfer. Figure 2 is the effect diagram of the airflow rotating device.

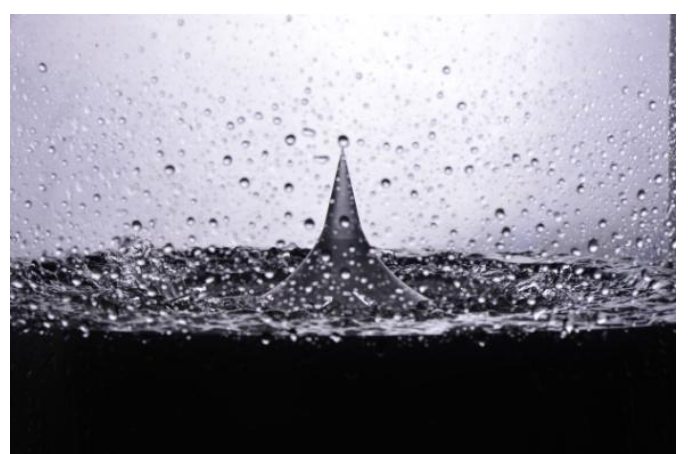

Fig.2 the effect diagram of the airflow rotating device

2.2 the innovative design of flue gas recycle system the flue gas recycle system is an innovative technology to ensure the effect of the flue gas hitting the liquid level. We design a concentric cylinder to improve the nozzle exit flue gas velocity and the impact effect. The concentric cylinder connect with the inlet of the circular flue gas and the conical nozzle to form a circular channel. This device send a part of the flue gas back to the gasification equipment to increase the velocity of flue gas at the vent, and strengthen the force of the gas hitting the water. The advantage of the scheme: First, the system intensive mix the cycle gas and combustion gas at the conical nozzle, this increase the velocity of smoke effectively and strength the impact force. Second, promote the heat release from smoke to water is beneficial to the heat transfer of the bottom tube. Third, by adjusting the quantity of the circular flue gas, the system can control the temperature of smoke effectively to adjust running of device. Fourth, the low-temperature recycle smoke can cooling and protect the ektexine of the combustor[14-15].

\section{3 the innovative design of flood pattern}

the flood pattern is an innovative technology to ensure the water level in water pool. On the top of the cycle gas channel, we design some water injection pipes along the burning outside wall. The water injection pipe are several circular stainless steel pipes with uniform pores, the tubes are wrapped by fine stainless steel wire to ensure that the water from the eyelet diffuse equably along the steel wire gauze. The advantage of the technology solution: First, this can ensure that the water level won't be too low to influence the effect of the smoke. Second, the cooling effect of injected water can also protect the ektexine of combustor from exceeding the insurance temperature. Third, steam from injected water and the mixed flue gas will eject together from nozzle, which can also enhance the impact of the flue gas. 


\section{THE INDUSTRIAL APPLICATION EXPERIMENT RESEARCH OF THE LNG RAPID EVAPORATION DEVICE}

The industrial application experiment research system of LNG rapid evaporation device is based on a LNG station which belongs to a natural gas pipeline network limited company. The task of this LNG station is: reserve excess natural gas at normal time and vaporize LNG in emergency. Obviously, the test system can guarantee the stability of LNG supply here. After gasification gas can be incorporated into the site of the intake pipe and form a closed loop test medium, this is beneficial for LNG gasification device industrial test.

The test system is formed by following parts: the device, the gas supply system, the LNG supply system, the gasification gas reverse-flow system, the water supply system, the flue gas recycling system, the instrument testing and automatic control system. The whole test system layout is shown in figure 3.

1.DN32 long handle cryogenic valve 2.DN20 long handle cryogenic valve 3.pneumatic diaphragm control valve 4.pressure measuring point 5.temperature measuring point 6.safety valve 7.fan 8.exhaust air shutter 9.circular flue gas damper 10.globe valve 11.intelligent gas turbine flow meter 12.gas regulator box 13.gas flow meter 14.solenoid valve 15.filter 16.burner 17.external gasification device

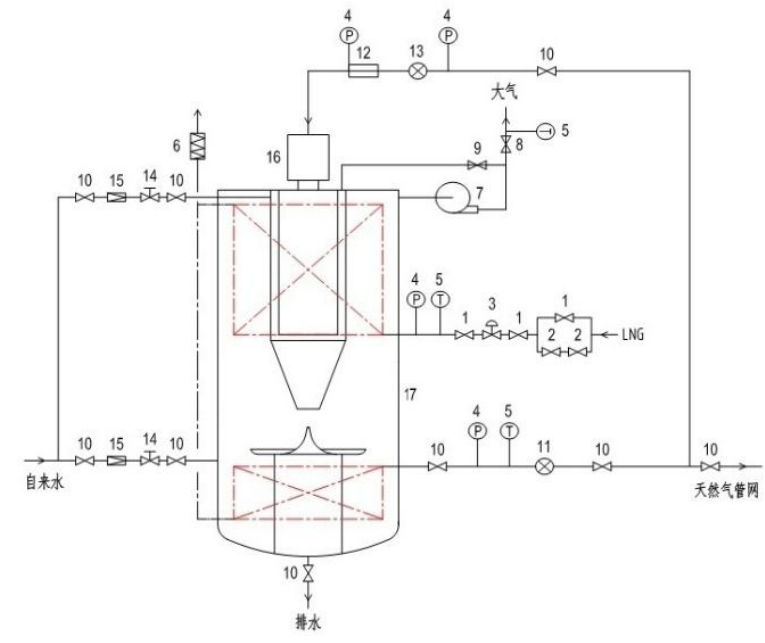

Fig. 3 the schematic diagram of the LNG rapid gasification device industrial application test system

There are the design parameters of the LNG quickly gasification industrial application device: The rated load is $2000 \mathrm{Nm} 3 / \mathrm{h}$, the LNG inlet pressure is $0.5-0.6 \mathrm{MPa}$, the natural gas outlet pressure is $0.4-0.5 \mathrm{MPa}$, the gas outlet temperature is $5-15^{\circ} \mathrm{C}$, the fuel is the natural gas pipeline. Under this circumstance, the efficiency of this device is $95.33 \%$, the flue gas and the heat loss are $2.67 \%$ and $1.5 \%$, this device's rate of air is $1.44 \%$. The test has done five working condition under this load, and the test date are shown in chart 1.

Chart 1 . The test data summary table of the LNG rapid gasification device

\begin{tabular}{l|l|l|l|l|l|l}
\hline Name & units & $\begin{array}{l}\text { Working } \\
\text { condition 1 }\end{array}$ & $\begin{array}{l}\text { Working } \\
\text { condition 2 }\end{array}$ & $\begin{array}{l}\text { Working } \\
\text { condition 3 }\end{array}$ & $\begin{array}{l}\text { Working } \\
\text { condition 4 }\end{array}$ & $\begin{array}{l}\text { Working } \\
\text { condition 5 }\end{array}$ \\
\hline Load & $\mathrm{Nm}^{3} / \mathrm{h}$ & 1744 & 1976 & 2228 & 2551 & 2808 \\
\hline $\begin{array}{l}\text { NG outlet } \\
\text { pressure }\end{array}$ & $\mathrm{MPa}$ & 0.502 & 0.520 & 0.528 & 0.535 & 0.546 \\
\hline $\begin{array}{l}\text { NG outlet } \\
\text { temperature }\end{array}$ & ${ }^{\circ} \mathrm{C}$ & 23.6 & 12.1 & 15.4 & 8.2 & 2.7 \\
\hline $\begin{array}{l}\text { LNG inlet } \\
\text { pressure }\end{array}$ & $\mathrm{MPa}$ & 0.537 & 0.560 & 0.570 & 0.579 & 0.598 \\
\hline
\end{tabular}

\section{THE RESULTS OF TEST AND ANALYSIS}

4.1 Check the design parameters of the new LNG gasification device

The chart 1 shows that: the scope of the experimental load is 1744-2808 Nm3/h, this fully meet the design requirements, especially its upper limit reached $140 \%$ of rated load. The socpe of the gasification gas outlet temperature is $2.7-23.6^{\circ} \mathrm{C}$, this meet the design requirements compare with the design value $5-15^{\circ} \mathrm{C}$, and the maximum temperature reached $157 \%$. The range of LNG inlet pressure is $0.537-0.598 \mathrm{MPa}$, the upper limit is almost the same as the design value but the lower limit is higher than $0.5 \mathrm{MPa}$. The gasification gas outlet pressure test range is $0.502-0.546 \mathrm{MPa}$, whose upper limit meets the requirement while lower limit is also higher than the design value.
The reason why the test can't lower the system pressure is that: Gasification test system is connected to the LNG station's gas inlet pipe network, the back pressure of the test system is the same as the inlet pressure of this LNG station, because the inlet pressure of the LNG station can't reduce, so as the test system pressure. But analysts believe that this takes little effect on the working performance of this device, because the outlet back pressure's reduce will increase the load adjusting amplitude, this is more benefit to the operation of the gasification device. Thus it can be seen that this device achieve the design requirements.

4.2 The efficiency of new LNG gasification device

According to the test data, we calculated the exergy of the positive and reverse balances and some other relevant 
Vol. 3, Issue 10, October 2016

parameters under various operating conditions, the results each working condition are all less than $2 \%$, therefore the are shown in chart 2 . The calculation results show that the result is valid. The efficiency of device is subject to the error of positive and negative balance efficiency under positive balance efficiency by regulation.

Chart2. The calculation data summary table of the LNG rapid gasification device

\begin{tabular}{l|l|l|l|l|l|l}
\hline Name & Units & $\begin{array}{l}\text { Working } \\
\text { condition 1 }\end{array}$ & $\begin{array}{l}\text { Working } \\
\text { condition 2 }\end{array}$ & $\begin{array}{l}\text { Working } \\
\text { condition 3 }\end{array}$ & $\begin{array}{l}\text { Working } \\
\text { condition 4 }\end{array}$ & $\begin{array}{l}\text { Working } \\
\text { condition 5 }\end{array}$ \\
\hline Load & $\mathrm{Nm}^{3} / \mathrm{h}$ & 1744 & 1976 & 2228 & 2551 & 2808 \\
\hline $\begin{array}{l}\text { Positive } \\
\text { balanced } \\
\text { efficiency }\end{array}$ & $\%$ & 95.02 & 96.34 & 95.23 & 94.38 & 93.20 \\
\hline $\begin{array}{l}\text { Negative } \\
\text { balanced } \\
\text { efficiency }\end{array}$ & $\%$ & 96.29 & 97.29 & 95.82 & 94.30 & 93.32 \\
\hline Flue gas loss & $\%$ & 3.62 & 2.66 & 4.09 & 5.59 & 6.55 \\
\hline Heat loss & $\%$ & 0.09 & 0.05 & 0.09 & 0.11 & 0.13 \\
\hline Air rate & $\%$ & 1.52 & 1.46 & 1.48 & 1.46 & 1.46 \\
\hline
\end{tabular}

Figure 4 shows the relationship between the efficiency of The design value of heat loss is $1.5 \%$, the test values are device and the change of the load. When the load is 1976.0 shown in table 2. When the load is $0.05 \%$ (condition 2), $\mathrm{Nm} 3 / \mathrm{h}$, the efficiency reach the peak value as $96.34 \%$, which is close to the design value, the loss can almost be which is higher than the design value $95.33 \%$; when the ignored compared with the design value. When the load load is between 1744 and $2228 \mathrm{Nm} 3 / \mathrm{h}$, the efficiency are deviate from the design value, the head loss increased, but all above $95 \%$, thus the LNG gasification device meet the this can also be ignored compared with the design value. design requirement in the range of the load. This proves This test shows that the heat loss is little. Because the that the device has strong load adaptability. As the load device is designed to ensure that the outer wall increasing, the device efficiency decline because of the temperature is low, thus reduce the heat loss effectively. overload operation. When the load is 2551 and The design value of the gas consumption rate is $1.44 \%$, the $2808 \mathrm{Nm} 3 / \mathrm{h}$, the efficiency is 94.38 and 93.20 , which are test values are shown in table 2 . When the load is all below the design requirement, but at this point the load $0.05 \%$ (condition 2), which is close to the design value, the reached $140 \%$. In the practical application, when the loss is almost the same as the design value, this meet the outside world emergency need the gas supply, it's design requirement. The gas consumption rate will acceptable that we reduce the efficiency to meet the increase in light load, the fuel quantity can't decline in demand of gas supply, the role of LNG gasification device order to keep the furnace combustion stability. The gas is more significant at that time.

4.3 The flue gas loss, the heat loss and the air rate of the new LNG quickly gasification device

The design value of exhaust loss is $2.67 \%$, the test values are shown in table 2. When the load is 1976.0 $\mathrm{Nm} 3 / \mathrm{h}$ (condition 2), which is close to the design value as $2000 \mathrm{Nm} 3 / \mathrm{h}$, the flue gas loss is $2.66 \%$, which is quite coincident with design data. But when the load deviate from the design value, especially when the operation is overload, the exhaust smoke rise quickly, which lead to the rapid drops in plant efficiency.

The reason is that, the fuel quantity won't reduce along with the decline of load for the stability combustion, the result will inevitably lead to exhaust temperature rise. While in high load, with the increase of fuel quantity and working medium heat absorption, the caloric receptivity won't rise along with the increase of fuel quantity because of the heat transfer effect. This result will lead to a shoot up of exhaust temperature and smoke exhaust rate. Obviously, the exhaust smoke loss is the main factors influencing the system efficiency. Control the exhaust temperature can effectively improve the device efficiency. consumption rate changed little in high load. It's clear that the device have a good energy saving effect.

\section{CONCLUSION}

(1) The new LNG gasification device is a new device using a lot of innovative technologies, such as the airflow rotating device, the flue gas recirculation system and the flood pattern. This device has been successfully used in industrial application test and the test parameters meet the design value. This device is suitable for following occasion: The relatively independent of small and medium-sized areas, the areas where require special gas parameters, the areas where need emergency reserve supply.

(2)The experimental results showed that: When the load is 1976.0 Nm3/h, the efficiency reached the peak value $96.34 \%$. When the load is between 1800 and $2200 \mathrm{Nm} 3 / \mathrm{h}$, efficiency are all above $95 \%$. Thus, this LNG gasification device has strong adaptability to load, the maximum load is up to $2800 \mathrm{Nm} 3 / \mathrm{h}$, this is able to adapt to the quickly increases of the outside world gas load. 
(3)Experimental results show that the main factors influencing the device efficiency is the exhaust loss, the device heat loss can almost be ignored. The device gas consumption rate is only $1.46 \%$, which meets powersaving and environmental-protection requirements.

\section{REFERENCES}

[1] Wong KKL, Cheung SCP, Yang WW, Tu JY (2010) Numerical simulation and experimental validation of swirling flow in spiral vortex ventricular assist device. International Journal of Artificial Organs 33: 856-867.

[2] Vun S, Naser JA, Witt PJ, Yang WW (2010) Measurements and numerical predictions of gas vortices formed by single bubble eruptions in the freeboard of a fluidised bed. Chemical Engineering Science 65: 5808-5820.

[3] Tim Burchell and Mike Rogers. Low Pressure Storage of Natural Gas. Government/Industry Meeting Washington, D.C. Jane. 19-21, 2000.

[4] $\mathrm{Gu}$ Anzhong. Liquefied natural gas technology [M]. Beijing: Mechanical Industry Press, 2004.8

[5] Jiang Zhenghou. Gas Engineering Handbook [M]. Shanghai: Tongji University press, 1993.5

[6] YAN Ping, CAO Weiwu, QIAN Shangyuan, etc. The structural design and experimental research of a new type of LNG heated and gasified device, Nature Gas Industry. 2011.6.

[7] YAN Ping, CAO Weiwu, QIAN Shangyuan, etc. The research and design of a new type of LNG gasified device using a method of flue gas lashing and sending up spray, Nature Gas Industry. 2011.1.

[8] He FaJiang, CAO Weiwu, YAN Ping, Experimental Investigation of Heat Transfer and Flowing Resistance for Air Flow Cross Over Spiral Finned Tube Heat Exchanger, Energy Procedia, ISSN 18766102, 2012, (17) : 741-749

[9] He FaJiang, CAO Weiwu, YAN Ping, Experimental Research on a New Vaporization of LNG using Flue Gas to Impact Underwater Umbrella Rotor to Enhance Heat Transfer, Energy Procedia, ISSN 1876-6102, 2012, (17) : 750-761.

[10] YAN Ping, CAO Weiwu, He FaJiang, etc. A device to maintain the water level of the LNG heating gasifier, China, ZL201210153604.0[P].2014-7.

[11] CAO Weiwu, YAN Ping, QIAN Shangyuan, etc. A kind of LNG heating gasification device using flue gas to impact the level, ZL201010113494.6[P].2012-1.

[12] YAN Ping, CAO Weiwu, QIAN Shangyuan, etc. A device for guiding airflow shocking the level to form the moisture, China, ZL201010113563.3 [P]. 2011-7.

[13] Zheng Yongxin, , YE YuanZhang Condensing gas water heater [M], Chongqing: Chongqing University Press, 2008.5.

[14] YAN Ping, CAO Weiwu, QIAN Shangyuan, etc. Research of flow field in large cylinder natural gas heating furnace and optimized arrangement of heat exchanging areas, Nature Gas Industry. vol. 30, pp. 119-122, 2, 2010.

[15] Cao JiaShen, Heat transfer and resistance properties for high frequency helically welding finned tube, Dongfang Electric Review, vol. 8, pp. 78-81, 1994 